\title{
Microglia Kv1.3 Channels Contribute to Their Ability to Kill Neurons
}

\author{
Christopher B. Fordyce, ${ }^{1,2}$ Ravi Jagasia, ${ }^{1,2}$ Xiaoping Zhu, ${ }^{1}$ and Lyanne C. Schlichter ${ }^{1,2}$ \\ ${ }^{1}$ Division of Cellular and Molecular Biology, Toronto Western Research Institute, University Health Network, Toronto, Ontario, Canada M5T 2S8, and \\ ${ }^{2}$ Department of Physiology, University of Toronto, Toronto, Ontario, Canada M5S 1A8
}

\begin{abstract}
Many CNS disorders involve an inflammatory response that is orchestrated by cells of the innate immune system: macrophages, neutrophils, and microglia (the endogenous CNS immune cell). Hence, there is considerable interest in anti-inflammatory strategies that target these cells. Microglia express Kv1.3 (KCNA3) channels, which we showed previously are important for their proliferation and the NADPH-mediated respiratory burst. Here, we demonstrate the potential for targeting Kv1.3 channels to control CNS inflammation. Rat microglia express Kv1.2, Kv1.3, and Kv1.5 transcripts and protein, but only a Kv1.3 current was detected. When microglia were activated with lipopolysaccharide or a phorbol ester, only the Kv1.3 transcript (but not protein) expression changed. Using a Transwell cell-culture system that allows separate drug treatment of microglia or neurons, we found that activated microglia killed postnatal hippocampal neurons through a process that requires Kv1.3 channel activity in microglia but not in neurons. A major neurotoxic molecule in this model was peroxynitrite, which is formed from superoxide and nitric oxide; thus, it is significant that Kv1.3 channel blockers reduced the respiratory burst, but not nitric oxide production, by the activated microglia. In addressing the biochemical pathway affected by Kv1.3 channel activity, we found that Kv1.3 acts via a different cellular mechanism from the broad-spectrum drug minocycline, which is often used in animal models of neuroinflammation. That is, the dose-dependent reduction in neuron killing by minocycline corresponded with a reduction in p 38 mitogen-activated protein kinase activation in microglia; however, none of the Kv1.3 blockers affected p 38 activation.
\end{abstract}

Key words: microglia activation; neurotoxicity; neuroinflammation; Kv channel roles; Kv expression; anti-inflammatory treatments

\section{Introduction}

Microglia, astrocytes, and oligodendrocytes are the main nonneuronal cells of the CNS. Microglia, the endogenous immune cells, are promising cellular targets for controlling CNS inflammation. They extend long processes that are in close proximity to most CNS cells. Thus, they are ideally positioned for immune surveillance and as immediate sensors of acute CNS injuries. In the healthy adult brain, microglia release neurotrophic molecules and growth factors, condition the extracellular environment through pinocytotic and endocytotic mechanisms, and phagocytose dead cells and debris (Polazzi and Contestabile, 2002; Streit, 2002). However, as for other immune cells, the defensive role of microglia can be subverted if they are overactive, present at the wrong time or place, or are directed against self, rather than foreign antigens. Indeed, there is growing evidence that microglia contribute to both acute and chronic CNS disorders (Kreutzberg, 1996; Gonzalez-Scarano and Baltuch, 1999; Stollg and Jander, 1999; Aloisi, 2001; Nelson et al., 2002; Polazzi and Contestabile, 2002). After almost all CNS insults, microglia undergo dramatic

Received March 31, 2005; revised May 19, 2005; accepted June 13, 2005

This work was supported by operating grants to L.C.S. from the Canadian Institutes for Health Research (MT13657) and the Heart and Stroke Foundation of Canada (T4670) and by an Ontario Graduate Scholarship to C.B.F. We are grateful to laboratory members Evan Newell and Dr. Xinpo Jiang for providing supporting electrophysiology information.

Correspondence should be addressed to Lyanne C. Schlichter, Toronto Western Hospital, MC9-417, 399 Bathurst Street, Toronto, Ontario, Canada M5T 2S8. E-mail: schlicht@uhnres.utoronto.ca. DOI:10.1523/JNEUROSCI.1251-05.2005

Copyright $\odot 2005$ Society for Neuroscience $\quad 0270-6474 / 05 / 257139-11 \$ 15.00 / 0$ phenotypic, immunochemical, and functional changes, collectively referred to as "activation." Some cellular functions of activated microglia include proliferation, migration to the injured site, recruitment of blood-borne immune cells, and synthesis of major histocompatibility complex class II molecules, with subsequent antigen presentation and phagocytosis of cells and debris (Gehrmann et al., 1995; Gebicke-Haerter et al., 1996; Streit et al., 1999; Aloisi, 2001; Schlichter and Khanna, 2002). Activated microglia can also produce neurotoxic products, and inflammation can exacerbate or even trigger damage in CNS diseases; thus, it is important to develop therapeutic strategies to control microglia activation in the CNS. Here, we investigated the potential for targeting specific $\mathrm{K}^{+}$channels.

Some ion channels are valuable drug targets for disorders that involve excitable cells (i.e., cardiac, skeletal, and smooth muscle, neurons), wherein specific $\mathrm{K}^{+}$channels regulate the membrane potential and $\mathrm{Ca}^{2+}$ influx. Although numerous studies have identified $\mathrm{K}^{+}$channels or currents in immune cells, their roles in cell functions and inflammatory disorders are poorly understood. Best characterized are the roles of voltage-gated Kv1.3 (KCNA3) and $\mathrm{Ca}^{2+} /$ calmodulin-activated (SK4/IKCa1/ KCNN4) $\mathrm{K}^{+}$channels in activation of lymphocytes (Cahalan et al., 2001; Schlichter and Khanna, 2002; Chandy et al., 2004). Indeed, blockers of these two channels are being tested in animal models of T-cell-mediated inflammatory diseases, including delayed-type hypersensitivity, multiple sclerosis, and restenosis of vascular smooth muscle cells (for review, see Cahalan et al., 
2001; Wulff et al., 2003; Chandy et al., 2004). The same two $\mathrm{K}^{+}$ channels are expressed in microglia (for review, see Eder, 1998; Schlichter and Khanna, 2002). We showed previously that Kv1.3 regulates microglia proliferation (Kotecha and Schlichter, 1999) and that both channels are involved in the respiratory burst (Khanna et al., 2001). In seeking new ways of controlling microglia activation, the present study examines roles of voltage-gated $\mathrm{K}^{+}$channels in their cytotoxic functions and killing of neurons. Our results demonstrate the potential for targeting Kv1.3 channels in microglia to reduce the neurotoxic outcomes of microglia activation.

\section{Materials and Methods}

Isolation and activation of microglia. Highly purified cultures of microglia (Khanna et al., 2001) were prepared from brains of postnatal day 2 or 3 Wistar rat pups (Charles River Laboratories, Saint-Constant, Quebec, Canada) as follows. The brain cortex was minced in cold Minimal Essential Medium (MEM; University Health Network, Toronto, Ontario, Canada), passed through a 100 -mesh screen, and seeded into $75 \mathrm{~cm}^{2}$ flasks in $30 \mathrm{ml}$ of MEM containing 5\% horse serum (v/v), 5\% fetal bovine serum, and $0.05 \mathrm{mg} / \mathrm{ml}$ gentamycin (all from Invitrogen, San Diego, CA). Cells were fed on day 2 , and after $7-12 \mathrm{~d}$ in culture (DIC), flasks were shaken $(8-12 \mathrm{~h}, 100 \mathrm{rpm})$, and the floating cells were harvested and plated for $1 \mathrm{~h}$ at $37^{\circ} \mathrm{C}$ and then washed to remove residual glial cells. The resulting culture was $98-100 \%$ microglia, as judged by staining with isolectin- $\mathrm{B}_{4}$, which binds to $\alpha$-D-galactose residues or with OX-42 antibody (anti$\mathrm{CD} 11 \mathrm{~b} / \mathrm{c}$ ), which recognizes the surface complement receptor 3. Subsequently, two types of serum-free media were used to reduce the spontaneous activation of microglia that usually occurs in culture. (1) For neuron-killing assays, microglia were washed, pelleted $(10 \mathrm{~min}, 200 \times \mathrm{g})$, and resuspended in serum-free Neurobasal A medium with 2\% B27 supplement (v/v), $0.5 \mathrm{~mm}$ L-glutamine, and $0.05 \mathrm{mg} / \mathrm{ml}$ gentamycin (all from Invitrogen) (Neurobasal A/B27 medium). These microglia $(1.5 \times$ $10^{6}$ per well) were plated on porous Transwell inserts (pore diameter, 3 $\mu \mathrm{m}$ ) in 12-well plates (BD Biosciences, Franklin Lakes, NJ). (2) For all other experiments, microglia were cultured in MEM containing astrocyte-conditioned medium (Eder et al., 1997). Specific activated functions of microglia can be stimulated by proinflammatory agents, including the bacterial endotoxin, lipopolysaccharide (LPS), tumor necrosis factor- $\alpha$, interferon- $\gamma$, or phorbol esters (Banati et al., 1991; Boje and Arora, 1992; Colton et al., 1994; Gebicke-Haerter et al., 1996; Smith et al., 1998; Khanna et al., 2001; Bal-Price et al., 2002; Ajmone-Cat et al., 2003; Lieb et al., 2003). Thus, we treated some microglia with LPS or phorbol 12-myristate 13-acetate (PMA), as indicated.

Postnatal rat neuron cultures. Neurons were prepared according to Brewer (1997) with minor modifications. Hippocampi were dissected from 2- to 3-d-old rats, incubated in $2 \mathrm{mg} / \mathrm{ml}$ papain (Worthington Biochemical, Lakewood, $\mathrm{NJ})\left(30^{\circ} \mathrm{C}, 30 \mathrm{~min}\right)$, and then triturated in Neurobasal A/B27 medium (see above). Neurobasal A/B27 medium is enriched in essential fatty acids, vitamins, and hormones and supports growth of postnatal and adult neurons (Brewer, 1997; Evans et al., 1998). Brewer's protocol uses the protease papain to gently separate neuronal connections and an Optiprep density gradient (Invitrogen) to increase the proportion of neurons. Next, the cells were transferred to Neurobasal A/B27 medium and plated onto poly-D-lysine (Sigma, St. Louis, MO)coated coverslips (Bellco Glass, Vineland, NJ) at $4 \times 10^{5}$ cells per coverslip. The cells were fed at 4 DIC by replacing one-half of the medium with fresh Neurobasal A/B27 and used at 7-10 DIC, at which time neuron purity was $>80 \%$, as assessed with a neuron-specific anti-mitogenactivated protein (MAP-2) antibody (Sigma). Almost all of the remaining cells were astrocytes, as indicated by staining with an antibody against glial fibrillary acidic protein; $<0.1 \%$ were microglia (OX-42 positive).

Reverse transcriptase-PCR. Total mRNA was extracted using the TRIzol method (Invitrogen, Burlington, Ontario, Canada). To eliminate genomic contamination, the cell suspension was subjected to DNase I (Amersham Biosciences, Dorval, Quebec, Canada) digestion $(0.1 \mathrm{U} / \mathrm{ml}$, $\left.15 \mathrm{~min}, 37^{\circ} \mathrm{C}\right)$. Total mRNA $(2 \mu \mathrm{g})$ was reverse transcribed at $42^{\circ} \mathrm{C}$ for 50 min in $20 \mu \mathrm{l}$ of $1 \times$ reverse transcriptase (RT) buffer [containing the following (in $\mathrm{mm}$ ): $75 \mathrm{KCl}, 50$ Tris, $\mathrm{pH} 8.3,3 \mathrm{MgCl}_{2}, 10$ dithiothreitol]

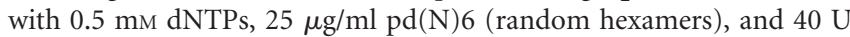
SuperScript II reverse transcriptase (all from Invitrogen). After firststrand cDNA synthesis, PCR amplification was conducted using a GeneAmp PCR 2400 system (PerkinElmer, Toronto, Ontario, Canada) with $1 \times$ PCR buffer (60 mM Tris-SO $\mathrm{m}_{4}$ pH 8.9, $18 \mathrm{~mm}$ ammonium sulfate), 2 $\mathrm{mm} \mathrm{MgSO}_{4}, 0.2 \mathrm{~mm}$ dNTPs, and $1 \mathrm{U}$ Platinum TaqDNA polymerase (Invitrogen) using gene-specific primers and conditions (see Table 1). The PCR mixture was incubated for $5 \mathrm{~min}$ at $95^{\circ} \mathrm{C}$, subjected to 35 cycles consisting of a $20 \mathrm{~s}$ denaturing phase at $94^{\circ} \mathrm{C}$, a $30 \mathrm{~s}$ annealing phase, a $30 \mathrm{~s}$ extension phase at $72^{\circ} \mathrm{C}$, and a final extension phase of $7 \mathrm{~min}$ at $72^{\circ} \mathrm{C}$. The resulting DNA products were resolved on 1-2\% agarose gels containing $0.5 \mathrm{mg} / \mathrm{ml}$ ethidium bromide, and product identities were confirmed by dideoxy sequencing (ACGT Laboratories, Toronto, Ontario, Canada). Band densities were measured using the Northern Eclipse 6.0 software (Empix Imaging, Mississauga, Ontario, Canada) and normalized to each internal control [ $\beta$ actin or glyceraldehyde-3-phosphate dehydrogenase (GAPDH)].

Western analysis. Microglia $\left(7.5 \times 10^{5}\right.$ per well $)$ in a six-well dish were rinsed in cold PBS and lysed in buffer containing the following: $50 \mathrm{mM}$ Tris, pH 8.0, 1\% Nonidet P-40, $150 \mathrm{~mm} \mathrm{NaCl}, 1$ mм EDTA, 2 mм $\mathrm{Na}_{3} \mathrm{VO}_{4}, 1 \mathrm{mM} \mathrm{NaF}$, and the protease inhibitors phenylmethylsulfonyl fluoride $(1 \mathrm{~mm})$, aprotinin $(1 \mu \mathrm{g} / \mathrm{ml})$, and leupeptin $(1 \mu \mathrm{g} / \mathrm{ml})$. The protein content of each lysate was measured using the Bradford assay (Bio-Rad, Mississauga, Ontario, Canada), then $50 \mu \mathrm{g}$ of each sample was boiled for $3 \mathrm{~min}$ in sample buffer [i.e., a 1:3 dilution of $3 \times$ sample buffer containing 6\% SDS, $187.5 \mathrm{~mm}$ Tris, pH 6.8, 138 mm DTT, 30\% glycerol, $0.03 \%$ phenol red (sodium salt)]. Proteins were separated by electrophoresis on an $8 \%$ SDS-polyacrylamide gel. Proteins were transferred to nitrocellulose polyvinylidene difluoride (PVDF) membranes (Bio-Rad), blocked with $5 \%$ nonfat milk in tris(hydroxymethyl) aminoethanebuffered saline (TBS) with $0.1 \%$ Tween 20 (TBST) or in PBS, and incubated with primary antibodies in blocking buffer for $2 \mathrm{~h}$ at room temperature or overnight at $4^{\circ} \mathrm{C}$. The membranes were washed (twice with TBST and twice with TBS or three times with PBS) and incubated (1 h, room temperature) with horseradish peroxidase-conjugated secondary antibody (1:3000; Cedarlane Labs, Hornby, Ontario, Canada) in blocking buffer. After another wash cycle, labeled proteins were visualized by enhanced chemiluminescence on high-performance film (Hyperfilm TM; Amersham Biosciences). The primary antibodies and dilutions used were the following: polyclonal anti-Kv1.2 (1:100; Alomone Labs, Jerusalem, Israel), polyclonal anti-Kv1.3 (AU13; 1:1000; gift from Dr. Debra Fadool, Florida State University, Tallahassee, FL), polyclonal anti-Kv1.5 (UBI; 1:100), and monoclonal anti-GAPDH (1:10,000; Advanced Immunochemicals, Long Beach, CA). Band densities were normalized to each GAPDH internal control.

For p38 phosphorylation (activation) assays, microglia were lysed in $50 \mu \mathrm{l}$ of $3 \times$ gel-loading buffer containing the following: $210 \mathrm{~mm}$ Tris, $\mathrm{pH}$ $6.8,6 \%$ SDS, $1 \mathrm{~m} \mathrm{NaCl}, 120 \mathrm{~mm}$ dithiothreitol, $0.03 \%$ phenol red, and $30 \%$ glycerol and then scraped from the wells and immediately transferred to microfuge tubes on ice. Extracts were sonicated for $5 \mathrm{~s}$ to shear the DNA and reduce sample viscosity. The lysates were heated to 95$100^{\circ} \mathrm{C}$ for $5 \mathrm{~min}$, centrifuged for $30 \mathrm{~s}$, and $20 \mu \mathrm{l}$ of each sample was electrophoresed on an $8 \%$ SDS-polyacrylamide gel. Proteins were transferred onto a PVDF membrane, washed in TBST and then in TBS (two times, $10 \mathrm{~min}$ each), and incubated in a primary antibody diluted in blocking solution. First, phospho-p38 MAP kinase (MAPK) was measured, then the membrane was stripped with $0.1 \mathrm{M} \mathrm{NaOH}$ and reprobed with p38 MAPK antibody (both polyclonal antibodies were used at 1:750; Cell Signaling Technology, Beverly, MA). Membranes were washed and incubated with an HRP-conjugated anti-rabbit secondary antibody (1: 2000-1:3000; Cedarlane Labs). Band densities were measured, and phospho-p38 was normalized to total p38 in each sample.

Other chemicals. LPS (Sigma) was dissolved in PBS and stored at $4^{\circ} \mathrm{C}$; PMA was dissolved in DMSO and stored at $-20^{\circ} \mathrm{C}$. The peroxynitrite scavenger 5,10,15,20-tetrakis( $N$-methyl- $4^{\prime}$-pyridyl)porphinato iron (III) chloride (FeTmPyP; Calbiochem, La Jolla, CA) was stored at $-20^{\circ} \mathrm{C}$ and dissolved in distilled water before use. Five $\mathrm{K}$ channel blockers were used at sufficiently high concentrations to block the main channel of 
interest (Table 2), as follows. The broad-spectrum Kv1-family blocker 4 -aminopyridine (4-AP; Sigma) was stored at $4-6^{\circ} \mathrm{C}$ in PBS. The more potent and selective peptide toxins agitoxin-2 (AgTx-2), charybdotoxin (ChTx), and $\alpha$-dendrotoxin ( $\alpha$-DTx) were obtained from Alomone Labs and stored lyophilized at $-20^{\circ} \mathrm{C}$. Before use, each peptide toxin was dissolved in PBS with $0.1 \%$ BSA to reduce its adsorption onto glass or plastic.

Terminal deoxynucleotidyl transferase-mediated biotinylated UTP nick end labeling. Microglia alone, growing in 12-well plates on porous Transwell inserts, were left untreated or exposed to LPS for $18-24 \mathrm{~h}\left(95 \% \mathrm{O}_{2}\right.$, $5 \% \mathrm{CO}_{2}, 37^{\circ} \mathrm{C}$ ), with or without a $\mathrm{K}$ channel blocker, as indicated. Next, each microglia-bearing Transwell insert was rinsed and placed in a well of a 12-well plate in which postnatal hippocampal neurons were growing on glass coverslips. After $48 \mathrm{~h}$ of coincubation $\left(95 \% \mathrm{O}_{2}, 5 \% \mathrm{CO}_{2}, 37^{\circ} \mathrm{C}\right)$, neuronal death was determined by terminal deoxynucleotidyl transferase-mediated biotinylated UTP nick end labeling (TUNEL) (Roche Applied Science, Laval, Quebec, Canada) as follows. Neurons were washed in PBS ( 5 min, two times), permeabilized in Triton X-100 $(0.01 \%)$ and sodium citrate (1\%) on ice, washed again in PBS (5 min, two times), and fixed in $4 \%$ paraformaldehyde in PBS for $1 \mathrm{~h}$ at $20-25 \mathrm{C}^{\circ}$. After washing again in PBS (10 min, three times), coverslips were incubated with the reaction mixture, consisting of terminal deoxynucleotide transferase and fluorescein-labeled nucleotides for incorporation into DNA strand breaks. After a final washing in PBS (5 min, three times), coverslips were mounted in Slowfade (Molecular Probes, Eugene, OR) with $4^{\prime}, 6^{\prime}$-diamidino-2-phenylindole (DAPI), a fluorescent nuclearintercalating dye that was used to count total numbers of cells. Cells were viewed using a Zeiss (Oberkochen, Germany) Axioplan 2 Imaging microscope equipped with a Zeiss Axiocam digital camera and a $60 \times$ oilimmersion objective.

Respiratory burst. Production of reactive oxygen species by microglia was monitored according to Banati et al. (1991), with some modifications. Microglia $\left(1.5 \times 10^{5}\right.$ cells per well $)$ were plated in 12 -well plates and incubated overnight in culture medium (MEM containing astrocyteconditioned medium, as above). Just before use, the cells were washed and incubated for $5 \mathrm{~min}\left(95 \% \mathrm{O}_{2}, 5 \% \mathrm{CO}_{2}, 37^{\circ} \mathrm{C}\right)$ in $500 \mu$ of this medium, containing $20 \mu \mathrm{M}$ dihydrorhodamine-123 (DHR-123; Molecular Probes). DHR-123 readily diffuses into cells in which it is oxidized by cytochrome $\mathrm{C}, \mathrm{Fe}^{2+}$, or hydrogen peroxide and peroxidase to form the green fluorescent product rhodamine-123 (Banati et al., 1991). Next, $500 \mu \mathrm{l}$ of medium was added, with or without $300 \mathrm{nM}$ PMA and a K channel blocker, as indicated. PMA stimulates an NADPH-mediated respiratory burst in microglia (Smith et al., 1998). The cells were incubated for an additional $30 \mathrm{~min}\left(95 \% \mathrm{O}_{2}, 5 \% \mathrm{CO}_{2}, 37^{\circ} \mathrm{C}\right)$, washed several times with PBS, detached using $0.05 \%$ trypsin and $0.53 \mathrm{~mm}$ EDTA ( 5 min at $37^{\circ} \mathrm{C}$, then $10 \mathrm{~min}$ on ice), and resuspended in $600 \mu \mathrm{l}$ of FACS buffer (0.1\% BSA and 0.5 mm EDTA in PBS). DHR-123-loaded microglia were subjected to flow cytometry on a FACScan analyzer (BD Biosciences), reading the fluorescence intensity with an FL1 emission filter at 515-545 $\mathrm{nm}$. Sorting windows were set to exclude dead cells and debris, and 5000 microglia were counted for each experiment.

Nitric oxide production. Microglia were plated in 12-well plates in $1 \mathrm{ml}$ of culture medium at $5 \times 10^{5}$ cells per well. To measure nitric oxide (NO) production, the Griess reagent kit (Molecular Probes) was used to monitor accumulated nitrite and nitrate in the supernatants above microglia (Green et al., 1982), as follows. Supernatant (150 $\mu$ l) from each well was mixed with $130 \mu \mathrm{l}$ of distilled water and $20 \mu \mathrm{l}$ of equal parts $0.1 \% N$-(1-naphthyl)ethylenediamine dihydrochloride and $1 \%$ sulfanilic acid. The mixture was incubated for $30 \mathrm{~min}$ at room temperature, and then the optical density was measured at $540 \mathrm{~nm}$ using an ELISA plate reader (model EL311SX; Bio-Tek Instruments, Winooski, VT). For each experiment, a standard curve was constructed using known amounts of nitrite in culture medium. The supernatant was assessed immediately or frozen at $-80^{\circ} \mathrm{C}$ and assayed later.

Statistical analysis. All data are presented as the mean of each treatment group \pm the SEM, and statistical analyses were performed using Origin 7.0 software (Microcal Software, Northampton, MA). Unless otherwise specified, a one-way ANOVA with the Bonferroni's correction was used
Table 1. Primers used for RT-PCR

\begin{tabular}{lll}
\hline Gene & $\begin{array}{l}\text { Accession } \\
\text { number }\end{array}$ & Primers \\
\hline Kv1.2 & J04731 & $\begin{array}{l}\text { FP: CAC CGG GAG ACA GAG GGA } \\
\text { RP: TCA GAC ATC AGT TAA CAT }\end{array}$ \\
Kv1.3 & M30312 & $\begin{array}{l}\text { FP: AAT GAG TAC TTC TTC GAC CGC AAC AGA CCC AGC TTC GA } \\
\text { RP: CCA ATG AAA AGG AAA ATG AGC AGC CCC AG }\end{array}$ \\
Kv1.5 & M27158 & $\begin{array}{l}\text { FP: TGC AGA TCC TGG GTA AGA CC } \\
\text { RP: AGA GGG CAT ACA GGG ACC TC }\end{array}$ \\
$\beta$-Actin & Gl191581 & $\begin{array}{l}\text { FP: TGG AAT CCT GTG GCA TCC ATG AAAC } \\
\text { RP: TAA AAC GCA GCT CAG TAA CAG TCC G }\end{array}$ \\
GAPDH & M17701 & $\begin{array}{l}\text { FP: GGT CAG TGC CGG CCT CGT CTC AT } \\
\text { RP: CGC GCT CCT GGA AGA TGG TGA TG }\end{array}$ \\
\hline
\end{tabular}

FP, Forward primer; RP, reverse primer.

to determine whether there were statistically significant differences between groups.

\section{Results}

\section{Kv channel expression}

To assess whether Kv channel expression changes with activation, rat microglia were grown in astrocyte-conditioned medium to reduce their spontaneous activation (Eder et al., 1997) and then activated with the gram-negative bacterial endotoxin LPS. LPS is commonly used in vitro (Boje and Arora, 1992; Jeohn et al., 2002; Xie et al., 2002) and in vivo (Morimoto et al., 2002). The effect of overnight treatment with the protein kinase $\mathrm{C}$ activator PMA was also assessed. Using gene-specific primers (Table 1), mRNA expression was monitored for three Kv channels that we found previously in cultured rat microglia: Kv1.2, Kv1.3, and Kv1.5 (Kotecha and Schlichter, 1999) and standardized to a housekeeping gene in each sample (Fig. 1). Although we previously found low levels of Kv1.6 mRNA in cultured microglia (Kotecha and Schlichter, 1999), its expression was not examined because it was not involved in killing of neurons (see below). Only Kv1.3 transcript levels changed, with a $258 \%$ increase after LPS and a $237 \%$ increase after PMA treatment. Because transcript levels do not always correspond with protein expression, Western analysis was conducted on a large number of independent protein samples from microglia (Fig. 2). Kv1.2 and Kv1.5 protein levels were not affected, and, although there was a trend toward increased Kv1.3 protein after microglia activation with LPS or phorbol ester, it was not statistically significant. In the absence of stimuli, we previously observed no change in Kv1.3 or Kv1.5 protein levels when rat microglia were cultured for $\sim 3$ weeks (Khanna et al., 2001).

The Kv current amplitude was compared after treating microglia with a phorbol ester (PMA) for $1 \mathrm{~h}$ (Fig. 3) or overnight with $10 \mathrm{ng} / \mathrm{ml}$ LPS. In all microglia examined, the current activated in a time- and voltage-dependent manner at about $-40 \mathrm{mV}$, the activation rate increased with depolarization, and inactivation occurred over hundreds of milliseconds during positive voltage steps. Despite the presence of Kv1.2 and Kv1.5 channel protein, the only voltage-gated current detected appeared to be Kv1.3, because it was fully blocked by $5 \mathrm{~nm}$ agitoxin-2 (Fig. $3 A, B$ ), which potently blocks Kv1.3 ( $K_{\mathrm{d}}, \sim 200 \mathrm{pm}$ in T lymphocytes) (Grissmer et al., 1994; Garcia et al., 1997; Koo et al., 1997) but not Kv1.2 or Kv1.5 (Table 2). The current was not inhibited by $\alpha$-dendrotoxin (data not shown). To quantify the Kv1.3 current, the AgTx-2sensitive portion (which was at least $75 \%$ of the total current) was isolated by subtracting the current remaining in the presence of 5 nM AgTx-2. Under all conditions, the remaining current was not time dependent or voltage activated, it indicated an input resistance of 1-3 G $\Omega$ and was most likely leak or the anion current 


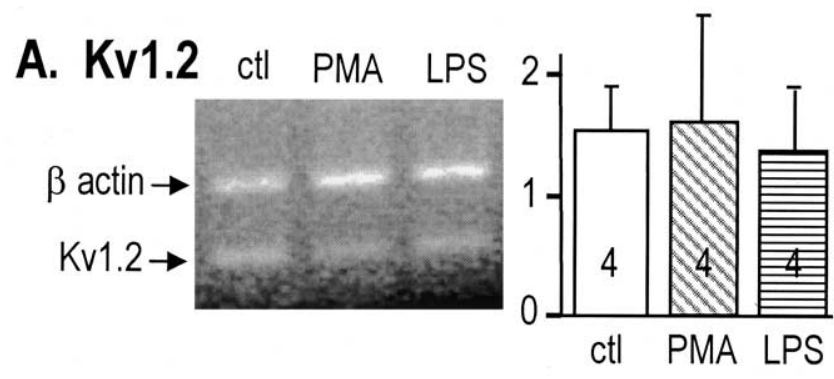

\section{B. Kv1.3 ctl PMA LPS}

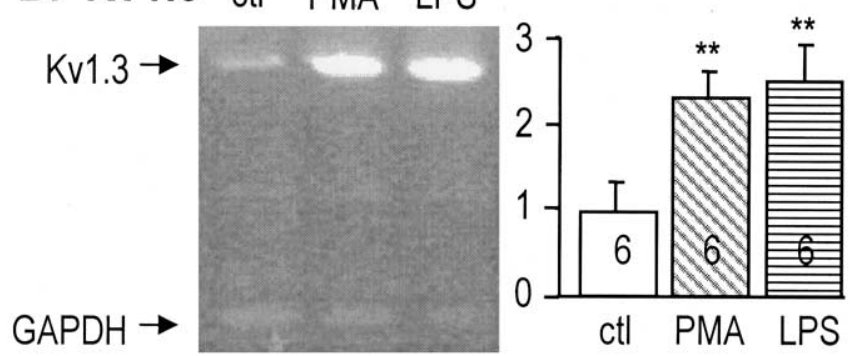

\section{Kv1.5 ctl PMA LPS}

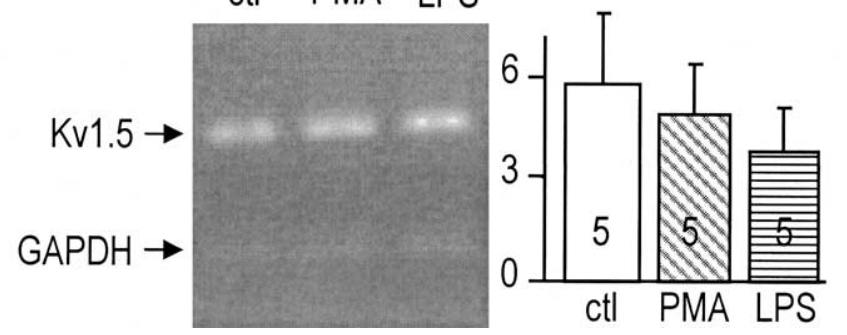

Figure 1. Kv channel transcript expression after microglia activation. $\boldsymbol{A}-\boldsymbol{C}$, Essentially pure rat microglia were left untreated [control (ctl)] or treated for $16 \mathrm{~h}$ with PMA (100 nM) or LPS (10 $\mathrm{ng} / \mathrm{ml})$. Left panels, Representative gels showing RT-PCR products for each Kv channel $(\boldsymbol{A}$, Kv1.2; $\boldsymbol{B}, \mathrm{Kv1.3;} \boldsymbol{C}, \mathrm{Kv1.5)}$ and an internal control in the same sample ( $\beta$-actin or GAPDH). Right, Each band density (in arbitrary units) was normalized to its internal control, and the mean \pm SEM is shown for the number of rat litters indicated on each bar. ${ }^{* *} p<0.01$.

described previously in these cells (Schlichter et al., 1996). The Kv1.3 current (AgTx-2-sensitive component) was then normalized to the cell capacitance to account for differences in cell size. Whereas short-term treatment with PMA had no effect, overnight LPS treatment increased the current at $+40 \mathrm{mV}(p<0.05$; $n=23$ ) (Fig. $3 C$ ). The $\sim 180 \%$ increase in Kv1.3 current could have resulted from increased surface expression of the channels (Kotecha and Schlichter, 1999) and/or increased channel activity, because LPS did not significantly increase the total Kv1.3 protein expression.

\section{Activated microglia kill neurons}

With Brewer's protocol (Brewer, 1997; Evans et al., 1998), the percentage of mature hippocampal neurons increased with time. By $9 \mathrm{~d}$, the time used for neurotoxicity assays, $>80 \%$ of the cells expressed high levels of the neuron-specific marker MAP-2 and had substantial voltage-gated $\mathrm{Na}^{+}$and $\mathrm{K}^{+}$currents (Fig. 4A-C). Importantly, the remaining cells were astrocytes, with a very low incidence $(<0.1 \%)$ of microglia. A key advantage of the present study is that, with the porous well inserts (Zietlow et al., 1999; Polazzi and Contestabile, 2002; Xie et al., 2002), we could separately treat either microglia or neurons, then wash them before
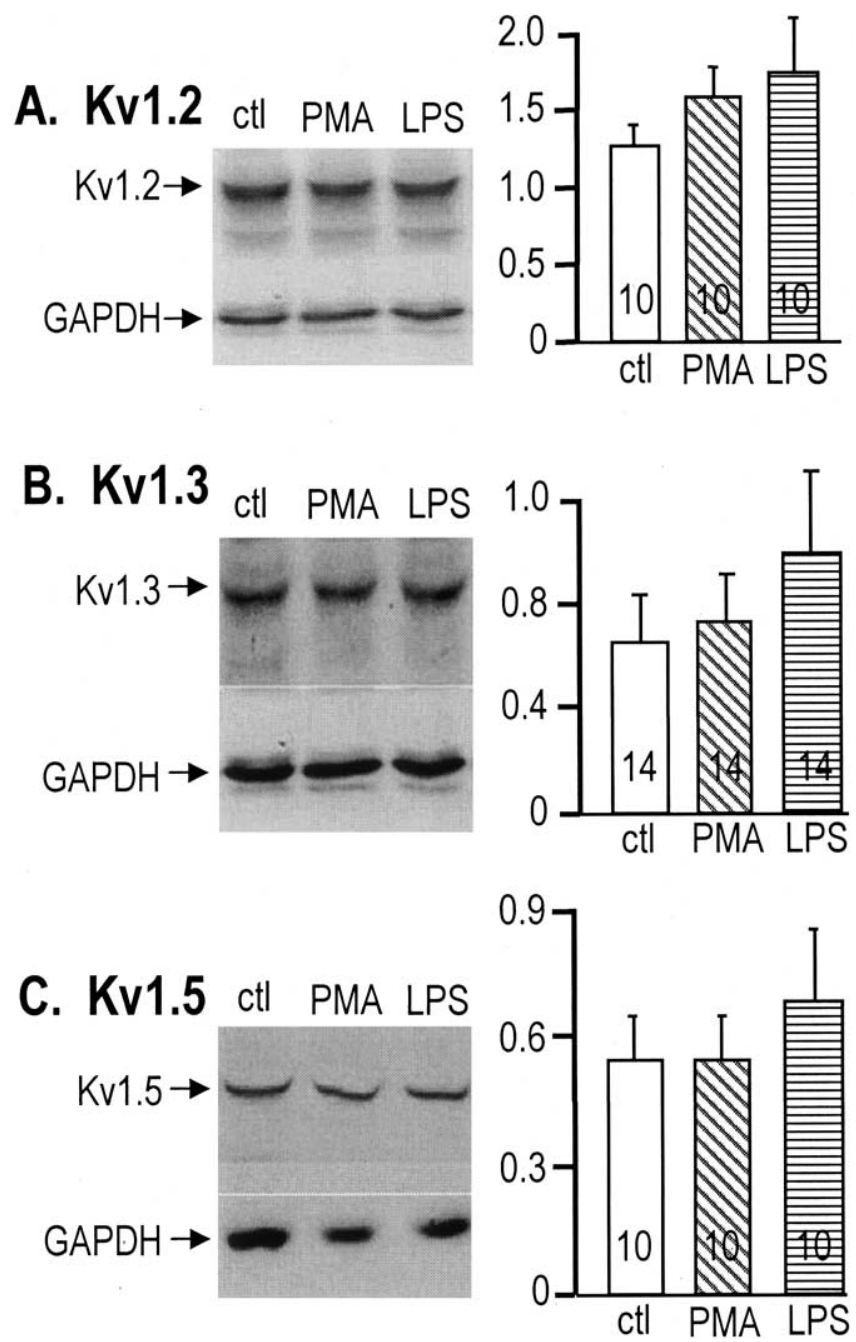

Figure 2. Protein expression of Kv channels after microglia activation. Microglia were treated as in Figure 1. $\boldsymbol{A}-\boldsymbol{C}$, The left panels show representative Western blots (A, Kv1.2; $\boldsymbol{B}$, $\mathrm{Kv1.3;} \boldsymbol{C}, \mathrm{Kv1.5)}$. The anti-Kv1.2 antibody recognized a strong band of the expected size (67 kDa) and a weaker lower-molecular-weight band. The anti-Kv1.3 antibody recognized the expected $65 \mathrm{kDa}$ band, and the anti-Kv1.5 antibody recognized the expected $60 \mathrm{kDa}$ band. The blot was simultaneously (Kv1.2) probed for the smaller housekeeping protein GAPDH or was cut and the lower portion separately probed for GAPDH (Kv1.3, Kv1.5). Right, Each band density (in arbitrary units) was normalized to its internal GAPDH control, and the mean \pm SEM is shown for the number of independent samples indicated. ctl, Control.

coincubation. Moreover, after the cells had communicated via diffusible factors in the medium, the neurons and microglia could be separated for further analysis. LPS is a potent microglial activator in vitro and triggers an inflammatory response and subsequent neurodegeneration in vivo (Boje and Arora, 1992; Jeohn et al., 2002; Morimoto et al., 2002; Xie et al., 2002). LPS-activated microglia have been shown to kill neurons by apoptosis, as judged by both TUNEL and caspase- 3 activation (Lee et al., 2004). We assessed the ability of LPS-activated microglia to kill neurons by calculating the percentage of TUNEL-positive cells, in which all cell nuclei were labeled with DAPI (Fig. $4 D$ ). In separate aliquots, we colabeled cells with TUNEL and MAP-2 to confirm that they were neurons, not astrocytes.

In control batches, spontaneous death of neurons cultured alone for the $3 \mathrm{~d}$ experimental period was $27 \pm 5 \%(n=5)$ (Fig. $4 E)$. Importantly, neuron death $(24 \pm 4 \% ; n=5)$ was the same when unstimulated microglia were placed in the upper chamber 


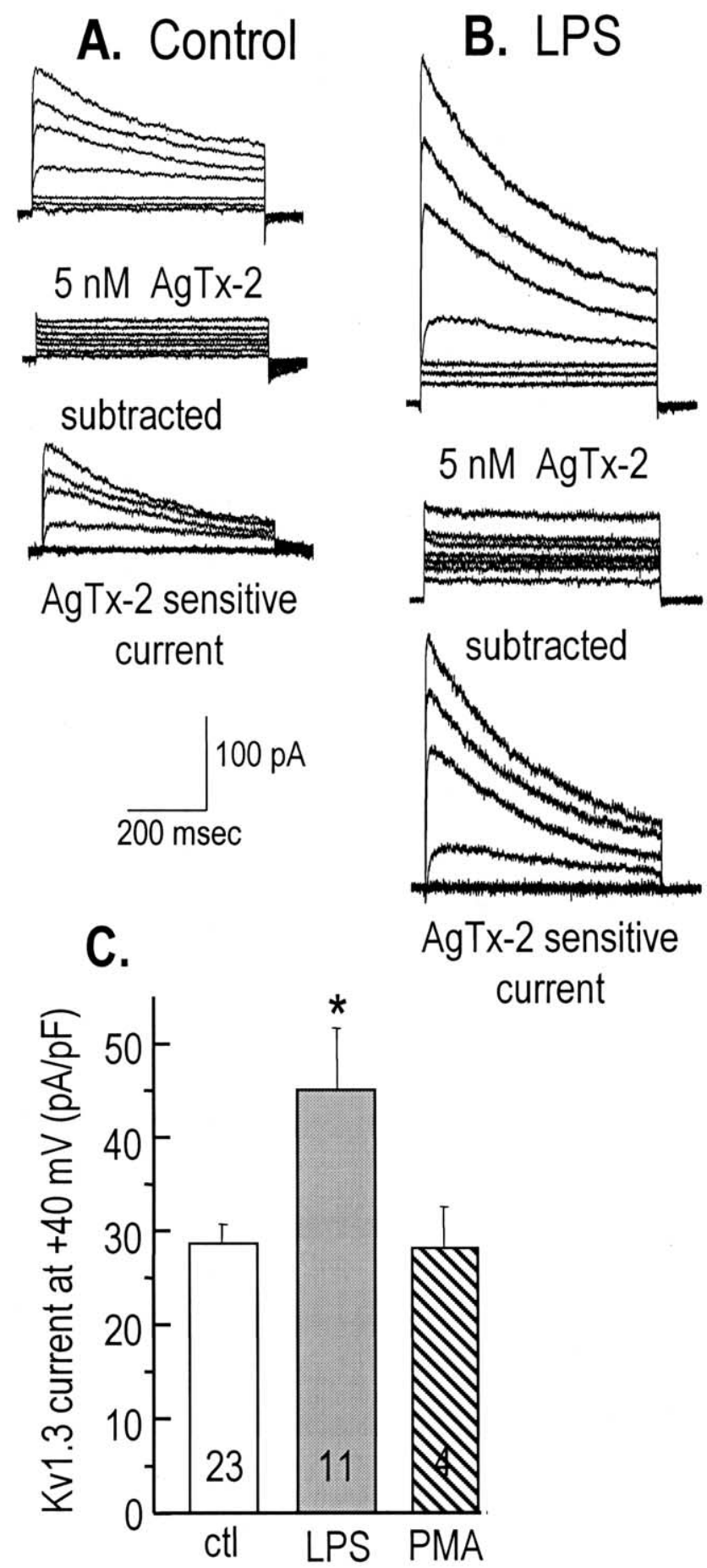

Figure 3. Microglia activation and Kv1.3 current. Conventional whole-cell recordings were made from microglia. The membrane potential was held at $-100 \mathrm{mV}$, and voltage steps were applied between -80 and $+40 \mathrm{mV}$ in $20 \mathrm{mV}$ increments. Representative currents are shown for an untreated microglia cell $(\boldsymbol{A})$ and one treated overnight with $100 \mathrm{ng} / \mathrm{mILPS}(\boldsymbol{B})$. Top, Recordings in normal bath solution; middle, after addition of $5 \mathrm{~nm}$ agitoxin-2; bottom, difference currents to isolate the AgTx-2-sensitive component. C, Summary of untreated [control (ctl)] cells or cells treated with LPS or PMA. Mean amplitude ( \pm SEM) of AgTx-2-sensitive (Kv1.3) current measured during a step to +40 $\mathrm{mV}$ and normalized to the cell capacitance (number of cells indicated on each bar). ${ }^{*} p<0.05$.

above neurons in the Transwell apparatus. In contrast, neuron death increased by $81 \%$ over the control level (to $42 \pm 3 \%$; $p<$ $0.05 ; n=11)$ when microglia were preactivated with LPS (100 $\mathrm{ng} / \mathrm{ml}$ ) and then washed and added to the neurons. For subsequent experiments, microglia were treated with $100 \mathrm{ng} / \mathrm{ml} \mathrm{LPS}$, because a higher concentration $(1000 \mathrm{ng} / \mathrm{ml})$ produced a similar level of neuron death $(37 \pm 4 \% ; n=3)$. Although the neurons were exposed to little or no LPS, we ensured that $100 \mathrm{ng} / \mathrm{ml}$ LPS alone was not directly toxic and had no effect on the survival of neurons. These results show that neurotoxicity required the presence of activated microglia, and none of the test compounds directly affected neuron survival.

\section{Blocking microglial Kv1.3 channels inhibits neurotoxicity}

The next step was to determine whether any of the $\mathrm{K}^{+}$channels in microglia affect their activation and ability to produce neurotoxic molecules. Blockers were selected for their ability to inhibit the $\mathrm{K}^{+}$channels that have been identified at the level of mRNA, protein, or ionic current in cultured microglia (i.e., Kv1.2, Kv1.3, Kv1.5, Kv1.6, and SK4). Blocker concentrations were chosen to substantially inhibit the current of interest (Fig. 5) while recognizing that none of the blockers is perfectly selective (Table 2). The top chamber containing microglia was incubated in a blocker and LPS and then washed three times before placing the chamber above the neuron-containing lower chamber. Although the naive test neurons were exposed to little if any blocker, as an added control, separate neurons were treated with the same concentration of each $\mathrm{K}^{+}$channel blocker, and no toxicity or excess neuron death was seen. Compared with the $81 \pm 6 \%$ increase in neuronal death caused by LPS-stimulated microglia, three of the channel blockers significantly reduced the killing. After microglia were treated with 4-aminopyridine, a broad-spectrum blocker of members of the Kv1 channel family, neuron death was reduced to $33 \pm 14 \%(p<0.05)$ above the control level. Charybdotoxin, which blocks Kv1.2, Kv1.3, and SK4 (all present in rat microglia) (Figs. 1, 2) (Khanna et al., 2001) reduced killing to $37 \pm 7 \%(p<$ $0.05)$, and agitoxin-2, which blocks Kv1.3 and Kv1.6, reduced killing to $32 \pm 10 \%(p<0.01)$. Interestingly, $\alpha$-dendrotoxin, which blocks Kv1.2 and Kv1.6, did not inhibit killing, thus ruling out a role for both channels. Because Kv1.3 is the only channel in microglia that is susceptible to all the neuroprotective blockers, this channel plays a critical role in LPS-induced neuron killing.

Kv1.3-mediated neuron killing involves the respiratory burst and peroxynitrite formation

Peroxynitrite, which is formed from superoxide and nitric oxide, has been found to be neurotoxic in previous studies (Bal-Price and Brown, 2001; Xie et al., 2002). Although the half-life of peroxynitrite itself is short, because generation of nitric oxide, superoxide, and other reactive oxygen species by LPS-stimulated microglia can continue for many hours, even days (Xie et al., 2002), peroxynitrite production can be sustained. To assess whether peroxynitrite was responsible for the microglia-mediated neuron killing, we used FeTmPyP, a specific decomposition catalyst that converts peroxynitrite to nitrate (Misko et al., 1998) without affecting superoxide production (Xie et al., 2002). Adding FeTmPyP $(2 \mu \mathrm{M})$ to a Transwell chamber containing neurons, astrocytes, and LPS-activated microglia (Fig. 6A) reduced neuron death from $81 \pm 6$ to $13 \pm 9 \%$ above the background level $(p<0.001 ; n=3)$, indicating that peroxynitrite plays a major role in killing neurons in this model. In separate control experiments on neurons and astrocytes, we ensured that the same concentration of FeTmPyP was not toxic and did not directly affect neuron death. We have not identified the cellular source of the nitric oxide and superoxide that produced the peroxynitrite in this model, but our experiments on pure microglia (below) provide additional information.

The neuroprotection by FeTmPyP implies that reducing pro- 
Table 2. Expected block of $\mathrm{K}^{+}$channels in microglia

\begin{tabular}{|c|c|c|c|c|c|}
\hline Drug (concentration used) & Kv1.2 $\left[K_{d}(\%\right.$ block $\left.)\right]$ & Kv1.3 $\left[K_{d}(\%\right.$ block $\left.)\right]$ & Kv1.5 $\left[K_{d}(\%\right.$ block $\left.)\right]$ & Kv1.6 $\left[K_{d}(\%\right.$ block $\left.)\right]$ & SK4 $\left[K_{\mathrm{d}}(\%\right.$ block $\left.)\right]$ \\
\hline 4-Aminopyridine (5 mм) & $590 \mu \mathrm{M}(89 \%)$ & $195 \mu \mathrm{M}(96 \%)$ & $270 \mu \mathrm{M}(95 \%)$ & $1500 \mu \mathrm{M}(77 \%)$ & \\
\hline Charybdotoxin (50 nм) & 14 nм $(78 \%)$ & $2.6 \mathrm{~nm}(95 \%)$ & $>7000 \mathrm{~nm}$ & $>7000 \mathrm{~nm}$ & 2 nм (96\%) \\
\hline Agitoxin-2(5 nм) & & $4 \mathrm{pm}(>99.9 \%)$ & & 40 рм (99\%) & \\
\hline$\alpha$-Dendrotoxin (50 nм) & 17 nм (75\%) & & & 20 пм (71\%) & \\
\hline
\end{tabular}

References: Grissmer et al., 1994; Garcia et al., 1997; Cahalan et al., 2001; Schlichter and Khanna, 2002; Chandy et al., 2004.

duction of either superoxide or nitric oxide should be neuroprotective. Thus, we assessed the ability of the $\mathrm{K}^{+}$channel blockers to inhibit their production by microglia. The respiratory burst and consequent production of superoxide, hydroxyl free radicals, and hydrogen peroxide can be stimulated in vitro by phorbol esters through protein kinase C activation (Colton et al., 1994; Smith et al., 1998; Spranger et al., 1998; Bal-Price et al., 2002). We exposed cultured rat microglia to PMA (150 nM), and the respiratory burst (with or without $\mathrm{Kv}$ channel blockers) was monitored by flow cytometry after DHR-123 loading (see Materials and Methods). The time course of the fluorescence signal was first monitored for 15-120 min in microglia preloaded with DHR-123 for 5 min and then stimulated with PMA in the continued presence of DHR-123. The fluorescence reached a plateau at $60 \mathrm{~min}$, which was then used for subsequent experiments. To confirm that the fluorescence signal was generated by an NADPH-mediated respiratory burst, we used the NADPHoxidase inhibitor diphenylene iodonium (DPI; $5 \mathrm{nM}$ ) (Khanna et al., 2001). PMA caused a significant increase in respiratory burst (by $164 \pm 2 \%$; $p<0.05$ ). As a negative control, when $100 \mathrm{~nm}$ of the inactive phorbol ester analog $4 \alpha$-PMA was added to the bath solution instead of PMA, it had no effect (Fig. 6B). Two Kv channel blockers dramatically inhibited the respiratory burst in pure microglia cultures (Fig. 6C). That is, 4 -aminopyridine, at a concentration that blocks all of the Kv1 channel types we have identified in rat microglia, reduced the increase in respiratory burst from $164 \pm 2$ to $6.1 \pm 8.9 \%$ above the control level $(p<0.01)$. Agitoxin-2, at a concentration that should block essentially all of the Kv1.3 and Kv1.6 channels, reduced the increase in respiratory burst to $14.5 \pm 8.2 \%(p<0.05)$. In contrast, $\alpha$-dendrotoxin, which blocks Kv1.2 and Kv1.6, did not inhibit the respiratory burst. Hence, this panel of $\mathrm{Kv}$ channel blockers demonstrates an important role for Kv1.3 and rules out the need for Kv1.2, Kv1.5, and Kv1.6.

Peroxynitrite formation requires $\mathrm{NO}$, and inducible nitric oxide synthase and subsequent NO production by activated microglia can be neurotoxic (Boje and Arora, 1992; Chao et al., 1992; Xie et al., 2002; Lieb et al., 2003). Thus, we assessed whether Kv channels contribute to NO production by monitoring nitrite levels (Green et al., 1982) accumulating in the culture medium of microglia exposed to LPS (Bal-Price and Brown, 2001). First, pure microglia cultures were stimulated with a range of LPS concentrations (1-1000 ng/ml) for 3-24 h to determine an appropriate concentration and duration of treatment. Consistent with other studies (Nakamura et al., 1999; Dijkstra et al., 2001), 10 $\mathrm{ng} / \mathrm{ml}$ LPS was adequate and produced a detectable increase in $\mathrm{NO}$ within $3 \mathrm{~h}$. Because there was no additional increase after $12 \mathrm{~h}$, this time point was used for subsequent experiments (Fig. $6 D)$. To control for variable baseline NO production, results were standardized to the control levels from unstimulated microglia in each cell batch. LPS increased NO production by $152 \pm$ $16 \%(p<0.01 ; n=4)$, and this increase was not affected by any of the Kv channel blockers; thus, none of the Kv channels we detected in microglia (Kv1.2, Kv1.3, Kv1.5, Kv1.6) appear to be needed for nitric oxide release. p38 MAPK activation and microglia-mediated neuron killing Activation of p38 MAP kinase in microglia is an important upstream regulator of production of numerous potential neurotoxins, including proinflammatory cytokines and reactive nitrogen species (Jeohn et al., 2002; Koistinaho and Koistinaho, 2002). Hence, we assessed whether the neuroprotective effect of Kv1.3 channel blockers is through interference with p38 MAPK phosphorylation and consequent activation. Because minocycline, which is a strong inhibitor of microglia activation, is known to reduce p38 activation in microglia (Chen et al., 2000; Tikka et al., 2001; Wu et al., 2002), we compared it to the Kv channel blockers. The upper and lower chambers of the Transwell apparatus were separated, and only microglia were treated with LPS with or without varying concentrations of minocycline. Then, the microglia chamber was washed three times before it was placed on top of the neuron chamber (Fig. 7A). The microglia were not in physical contact with neurons, and because minocycline is lipophilic, it is very unlikely that any remaining drug reached the neurons. Minocycline reduced neuron killing by LPS-activated microglia in a dose-dependent manner, with a calculated $\mathrm{IC}_{50}$ value of $\sim 90 \mathrm{nM}$.

LPS induced a transient phosphorylation (activation) of p38 MAPK, with a peak at $30 \mathrm{~min}$ (Fig. $7 \mathrm{~B}$ ), a time course that is consistent with previous studies (Ajmone-Cat et al., 2003). As expected, minocycline significantly inhibited phosphorylation of p38 MAPK (Fig. 7C) [i.e., to $72 \pm 6 \%$ of the LPS-induced level $(p<0.05 ; n=6)$ (Fig. $7 E)]$. Although the inhibition of $\mathrm{p} 38$ was not as profound as the inhibition of neuron killing by minocycline-treated microglia, both are consistent with previous reports (Chen et al., 2000; Tikka et al., 2001; Wu et al., 2002) and likely indicate that other pathways are also involved. Most importantly, none of the Kv channel blockers reduced p38 MAPK phosphorylation (Fig. $7 D, E$ ), thus ruling out direct or indirect inhibition of this kinase in the neuroprotective effect we observed with the Kv1.3 channel blockers.

\section{Discussion}

There are several key findings in this study. (1) Rat brain microglia express Kv1.2, Kv1.3, and Kv1.5 transcripts and protein, but only the Kv1.3 transcript expression increased when cells were activated with LPS or phorbol ester. Consistent with our previous reports (Schlichter et al., 1996; Kotecha and Schlichter, 1999; Khanna et al., 2001; Schlichter and Khanna, 2002), the only Kv current detected in the present study was essentially identical to

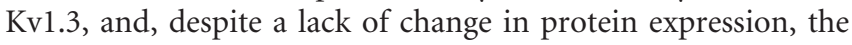
current was increased after LPS treatment. (2) Because almost nothing is known about the roles of $\mathrm{K}^{+}$channels in microglia, we exploited a well insert model that allows separate drug treatment of microglia (not neurons or astrocytes). We found that Kv1.3 channels in LPS-activated microglia contribute strongly to their ability to kill cultured postnatal hippocampal neurons. (3) We confirmed that peroxynitrite (which requires superoxide and nitric oxide production) contributes strongly to the observed neuron killing and that Kv1.3 channels are needed for the respiratory burst but not for nitric oxide production by microglia. (4) We found that the signal transduction pathway affected by Kv1.3 

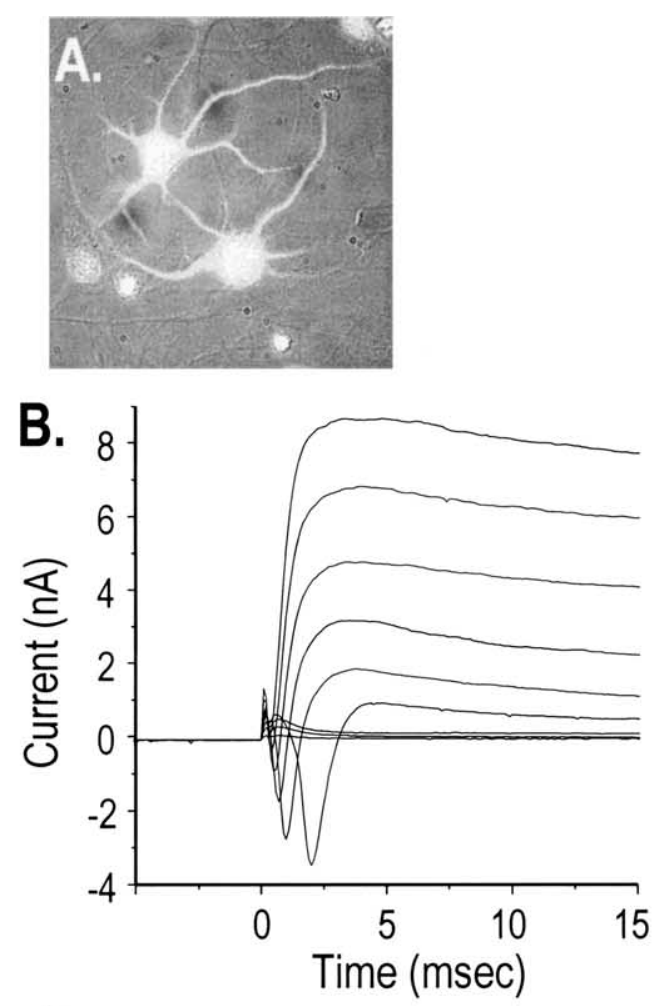

C.
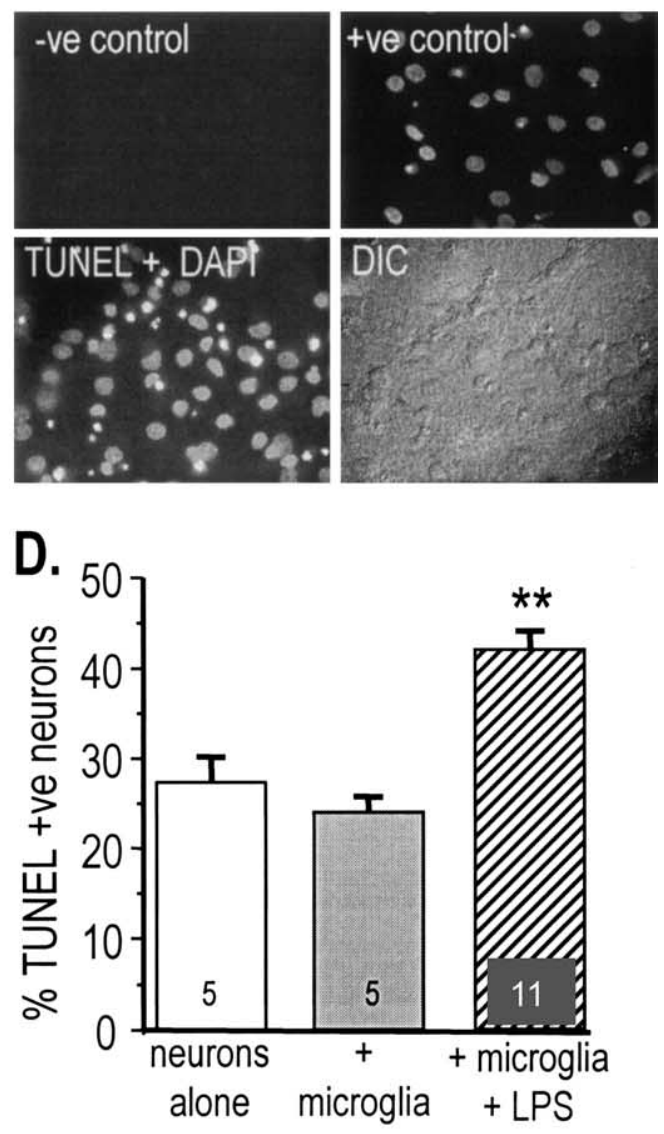

Figure 4. Activated microglia kill neurons. A-C, Properties of postnatal hippocampal neurons grown in Neurobasal A/B27 medium. Immunofluorescence image with differential interference contrast image overlaid $(\boldsymbol{A})$ of fixed and permeabilized postnatal neurons after $5 \mathrm{DIC}$ in serum-free Neurobasal A/B27 medium. All cell nuclei were labeled with DAPI, and the somatodendritic compartments of mature neurons were labeled with an anti-MAP-2 monoclonal

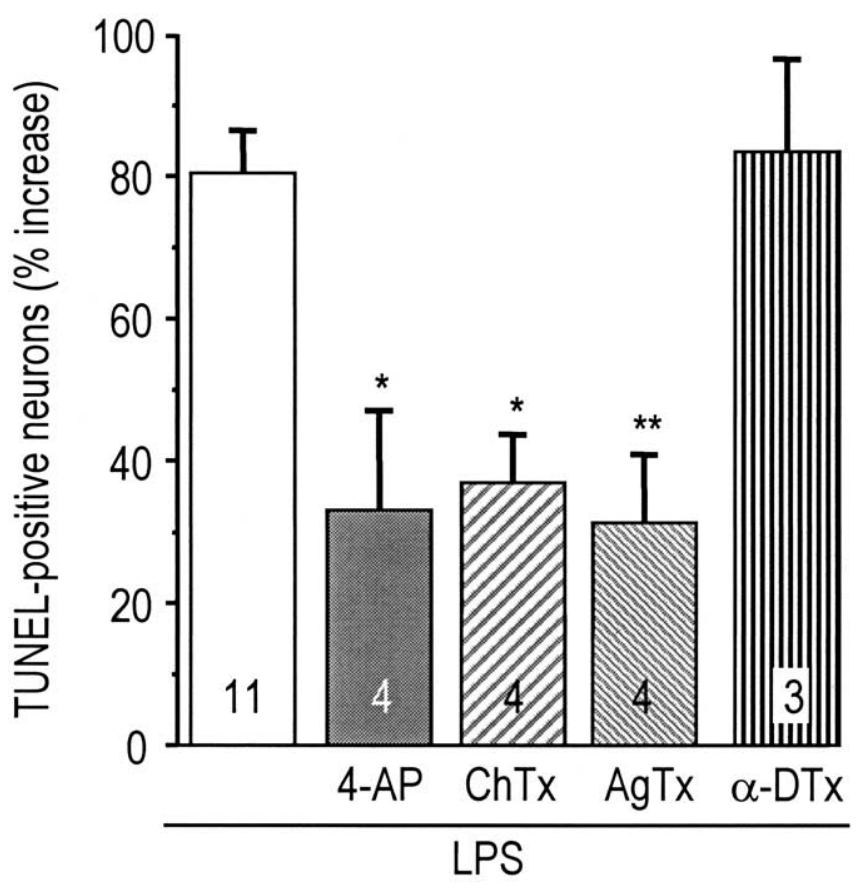

Figure 5. Kv1.3 blockers reduce neuron killing by microglia. Microglia were grown on membranes in the upper Transwell chamber, then treated with LPS (as in Fig. 4), with or without a $\mathrm{K}^{+}$channel blocker, and then washed three times before placing them above neurons in the lower Transwell chamber. The percentage channel block was calculated as $1 /\left[1+\left(K_{d} /[D]\right)\right]$, where $[D]$ is the concentration of blocker used in the experiment. From the $K_{d}$ values in Table 2, ChTx (50 nm) blocks 78\% of Kv1.2, 95\% of Kv1.3, and 96\% of SK4 channels; AgTx (5 nm) blocks $\sim 100 \%$ of Kv1.3 and Kv1.6 channels; $\alpha$-DTx (50 nm) blocks 75\% of Kv1.2 and $71 \%$ of Kv1.6 channels. Neuron killing was assessed by TUNEL as in Figure 4 and is expressed as the mean \pm SEM for the number of independent experiments indicated on each bar. ${ }^{*} p<0.05$; ${ }^{* *} p<0.01$.

channel blockade in LPS-activated microglia is independent of p38 MAP kinase activation, the inhibition of which is seen with the commonly used, broad-spectrum neuroprotectant minocycline. By affecting a different pathway, Kv1.3 channels offer a new mechanism for reducing neurotoxicity. Although no similar studies have been reported, some specific aspects of the current work can be compared with previous studies.

Most studies of cultured microglia describe a $\mathrm{K}^{+}$current that is essentially identical to Kv1.3 in its voltage and time dependence and block by 4 -aminopyridine, charybdotoxin, margatoxin, and agitoxin-2 (Norenberg et al., 1994; Schlichter et al., 1996; Visentin and Levi, 1997; Eder, 1998; Schlichter and Khanna, 2002); however, discrepancies exist concerning changes in $\mathrm{K}^{+}$channel expression under various conditions. There is some evidence that the $\mathrm{Kv}$ current in microglia can be increased by proinflammatory stimuli (e.g., LPS, interferon- $\gamma$ ), but large currents have also been

$\leftarrow$

antibody. Scale bar, $20 \mu \mathrm{m}$. Representative whole-cell voltage-clamp recordings $(\boldsymbol{B})$ from a neuron after $9 \mathrm{DIC}$ in Neurobasal A/B27. From a holding potential of $-100 \mathrm{mV}$, voltage steps were applied in $20 \mathrm{mV}$ increments from -80 to $+80 \mathrm{mV}$. C, D, Diffusible factors from activated microglia kill neurons. $C$, A representative experiment. Top, Postnatal hippocampal neurons growing in the bottom chamber of the Transwell apparatus, showing negative (no terminal transferase added) and positive controls (DNase I added) for the TUNEL assay. Bottom left, An upper chamber containing a porous insert with microglia was pretreated with LPS $(100 \mathrm{ng} / \mathrm{ml}$; $18-24 \mathrm{~h}$ ), washed three times, and then placed above the lower chamber containing neurons. After $48 \mathrm{~h}$, cells in the lower chamber were labeled with DAPI and TUNEL. Bottom right, Differential interference contrast image of same field of cells. $D$, Summary of neuron death (percentage TUNEL-positive cells); mean \pm SEM, number of independent experiments indicated on each bar. ${ }^{* *} p<0.01$. - ve, Negative; +ve, positive. 
recorded under conditions thought to suppress microglia activation (e.g., after culture in astrocyte-conditioned medium, granulocyte-macrophage colonystimulating factor, or TGF- $\beta$ ) (for review, see Eder, 1998; Schlichter and Khanna, 2002). In order for a channel to be an amenable target for drug therapy, it must be present on the cell surface. It is significant that we observed an increase in Kv1.3 current amplitude without a change in channel protein expression after LPS treatment. The two most likely explanations are an increase in channel activity by posttranslational modulation or an increase in channel expression on the membrane. Although the present study does not address the mechanism, we previously reported a marked change in membrane expression of Kv1.3 and Kv1.5 channels in microglia within tissue prints from rat hippocampal slices (Kotecha and Schlichter, 1999). The cells initially had robust Kv1.5 currents as a result of abundant Kv1.5 protein expression on the cell surface. Then, as the tissue prints were cultured, the current in microglia changed to Kv1.3, coincident with a switch in membrane localization of Kv1.3 and Kv1.5 protein. Kv1.3 channel activity is known to be affected by posttranslational modulation by serine/threonine or tyrosine phosphorylation in immune cells (Chung and Schlichter 1997a,b; Cayabyab et al., 2000; Schlichter and Khanna, 2002).

We found that cultured postnatal neurons were killed by microglia that had been activated with LPS. Activation of the neurotoxic functions of rat microglia was inhibited by all the drugs that block Kv1.3 channels (4-aminopyridine, charybdotoxin, agitoxin-2) but not by the Kv1.2 blocker $\alpha$-dendrotoxin. The extent of neuron killing was similar to a previous study (Xie et al., 2002); however, in that study, effects of LPS on microglia could not be distinguished from those on neurons because both cell types were exposed simultaneously to LPS. Another study (Wei et al., 2003) added the nonselective $\mathrm{K}^{+}$channel blocker tetraethylammonium to mixed cortical cultures in the presence of inhibitors of excitatory amino acid receptors. Although neuron death in response to oxygen-glucose deprivation was reduced, it is unclear which cell type or specific $\mathrm{K}^{+}$channels were involved. Thus, a key result from the present study is that the neurotoxicity of activated microglia was reduced by exposing the microglia (not the neurons) to peptide toxins that block Kv1.3 channels, and a contribution from the other $\mathrm{Kv}$ channels we identified in microglia was ruled out.

Despite numerous papers on ion currents in microglia (for review, see Eder, 1998; Schlichter and Khanna, 2002), the challenge of determining their roles in microglia functions has been sorely neglected. Some previous studies show that neurotoxicity of microglia can involve peroxynitrite (van der Veen et al., 1997;

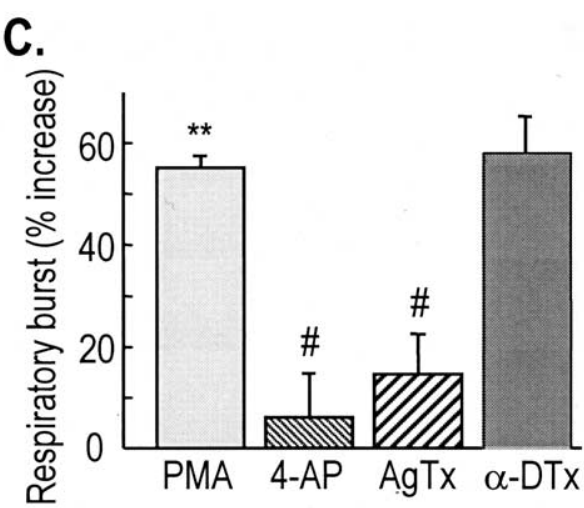

D.

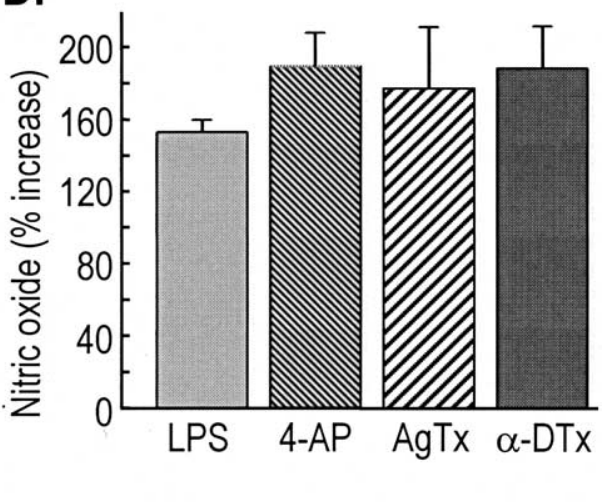

Figure 6. Mechanism of Kv1.3-mediated neuron killing. A, Microglia-dependent killing is caused by peroxynitrite. Microglia respiratory burst in microglia. In separate wells, microglia alone were untreated [control (ctl)] or treated with PMA (150 nM), an inactive analog ( $4 \alpha$-PMA; $150 \mathrm{~nm}$ ), or the NADPH-oxidase inhibitor DPI (1 $\mu \mathrm{m})$. Each compound was added to cells in medium containing $2 \mu \mathrm{m}$ DHR-123, and the fluorescence was monitored by flow cytometry after $60 \mathrm{~min}$. For each experiment, 5000 cells presented as mean fluorescence intensity ( \pm SEM) in arbitrary units $\left({ }^{* *} p<0.01 ; n=4\right)$. C, Kv1.3 blockade inhibits the respiray burst by microglia. Microglia, with or without a Kv channel blocker, were subjected to flow cytometry after PMA treatment as with unstimulated microglia. The PMA-induced respiratory burst was inhibited by both compounds that block Kv1.3 $(5 \mathrm{~mm}$ 4-aminopyridine, 5 nм agitoxin-2; ${ }^{\#} p<0.05$ ) but not by the Kv1.2 and Kv1.6 blocker (50 nм $\alpha$-dendrotoxin). D, Nitric oxide production is not inhibited by the Kv channel blockers. Microglia were untreated (ctl) or treated with $10 \mathrm{ng} / \mathrm{ml}$ LPS for $12 \mathrm{~h}$, with or without a Kv blocker. Then, the concentration of nitrite (micromolar) released from 50,000 cells per well was determined using the Griess assay. Four replicates for each blocker were used from each of three microglia cultures. Data are presented as the relative percentage increase compared with unstimulated microglia ( \pm SEM; $n=4$ separate experiments).

Xie et al., 2002), a membrane-permeant molecule that causes DNA strand breaks and lipid peroxidation, inactivates metalloenzymes, and triggers release of proapoptotic factors from mitochondria. Because superoxide combines with $\mathrm{NO}$ to form peroxynitrite (Gehrmann et al., 1995; van der Veen et al., 1997; Gonzalez-Scarano and Baltuch, 1999; Xie et al., 2002), agents that inhibit either the respiratory burst or NO formation should be neuroprotective. It is well known that activated microglia can produce superoxide (Colton et al., 1994; Bal-Price et al., 2002) and nitric oxide (Boje and Arora, 1992; Chao et al., 1992; Xie et al., 2002; Lieb et al., 2003). Consistent with some previous studies (Bal-Price and Brown, 2001; Xie et al., 2002), in our model of neuron killing by LPS-activated microglia, FeTmPyP (a specific peroxynitrite decomposition catalyst) (Misko et al., 1998; Xie et al., 2002) dramatically reduced neuron death. Because it was added to the Transwell cocultures, we cannot rule out a contribution of microglia, astrocytes, and neurons to peroxynitrite pro- 


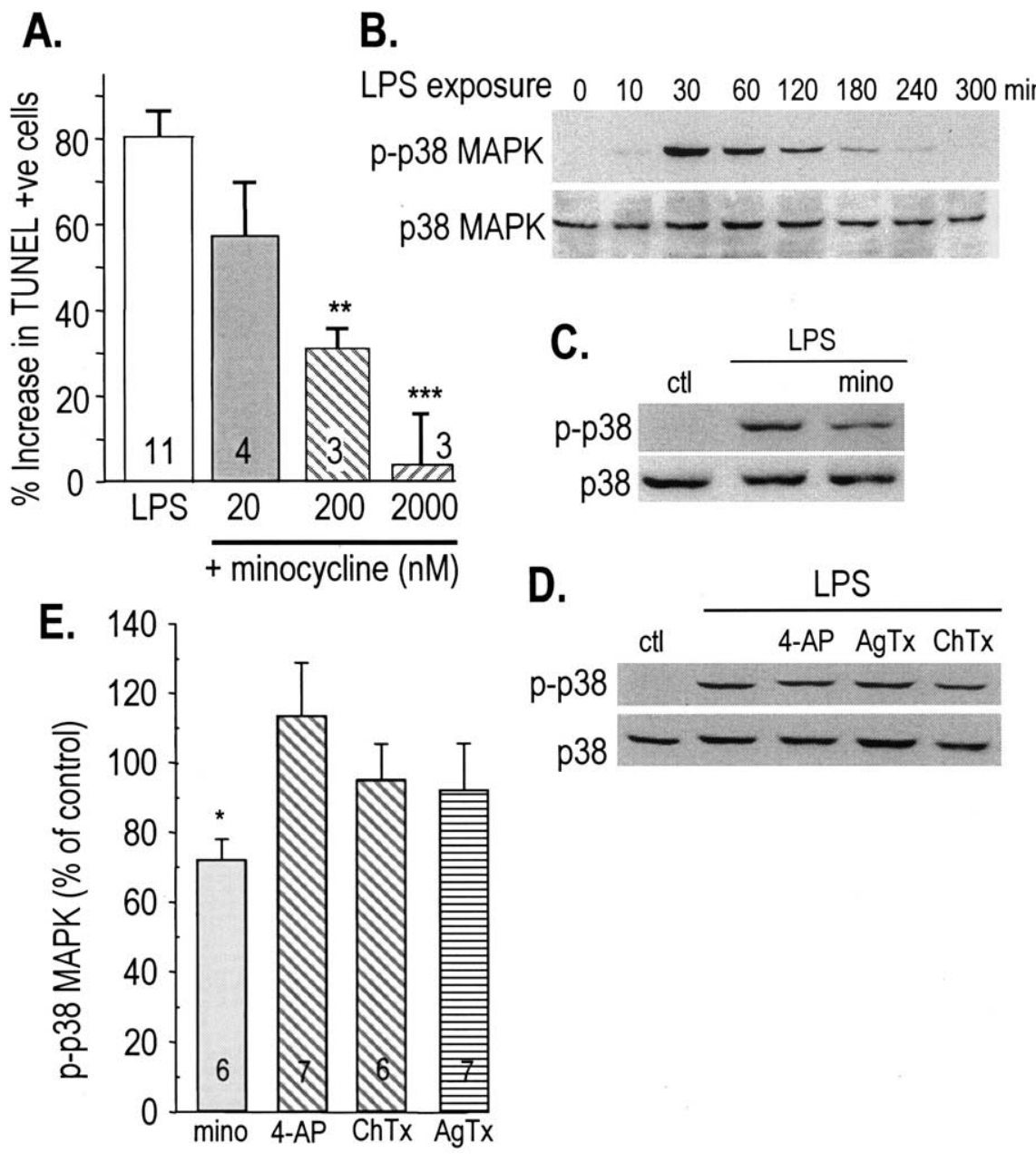

Figure 7. $\quad$ p38 MAPK activation. Effect of Kv blockers compared with minocycline. $\boldsymbol{A}$, Minocycline inhibits neuron killing by activated microglia. As in Figures 4 and 5, microglia growing in porous upper chambers of the Transwell apparatus were treated with LPS, with or without minocycline. The microglia were washed three times and then placed above postnatal hippocampal neurons growing in the bottom Transwell chamber. Neuron death was assessed by TUNEL after $48 \mathrm{~h}$, and expressed as the percentage increase in TUNEL-positive ( + ve) cells beyond that with unstimulated microglia (mean \pm SEM; number of independent cell cultures tested). ${ }^{* *} p<0.01 ;{ }^{* * *} p<0.001$. $\boldsymbol{B}$, LPS induces time-dependent activation of $\mathrm{p} 38$ MAPK. Cultured pure microglia were treated with LPS (100 ng/ml) and then lysed at the indicated times and subjected to Western blotting using an antibody that recognizes the activated, phosphorylated form of p38 MAPK. Then, the gel was stripped and reprobed with an antibody that recognizes total p38 MAPK. This gel, which is representative of three independent experiments, shows a transient p38 MAPK phosphorylation with a peak at 30 min. $\mathbf{C}-\boldsymbol{E}$, Minocycline (mino), but not Kv channel blockers, reduces LPS-induced p38 MAPK activation. Cultured pure microglia were treated with LPS $(100 \mathrm{ng} / \mathrm{ml})$ for 30 min with or without $200 \mathrm{~nm}$ minocycline $(\boldsymbol{C})$ or one of the Kv channels blockers (D) that was found to be neuroprotective (see Fig. 5): 4-AP ( $5 \mathrm{~mm}), \operatorname{AgTx}(5 \mathrm{~nm}), \mathrm{ChTx}(50 \mathrm{~nm})$. ctl, Control. Densitometric analysis (E) was used to assess p38 MAPK activation as in $\boldsymbol{B}$.

duction. However, an important finding in the present study is that the Kv1.3 channel blockers inhibited the respiratory burst (but not nitric oxide production) by microglia. Inhibition of the respiratory burst has been reported when either poorly selective $\mathrm{K}^{+}$channel blockers (Colton et al., 1994; Spranger et al., 1998) or more selective toxins were used (Khanna et al., 2001); however, only the present panel of toxins is sufficient to pinpoint Kv1.3 as the essential channel. The lack of effect on nitric oxide production is in accord with a previous study that used the broadspectrum Kv inhibitor 4-aminopyridine on LPS-treated microglia and macrophage cell lines (Brown et al., 1998). A report (Pyo et al., 1997) of reduced nitric oxide production after several days treatment of microglia with 4-aminopyridine failed to consider the potential cytotoxicity of this weak base (Kim et al., 2000).

In microglia, many proinflammatory stimuli cause phosphor- ylation (activation) of the mitogenactivated protein kinase p38 MAPK and consequent production of cytotoxic molecules, including nitric oxide (Jeohn et al., 2002; Koistinaho and Koistinaho, 2002). Similar p38 MAPK activation occurs in numerous acute and chronic brain disorders, including stroke, spinal cord injury, Alzheimer's disease, and Parkinson's disease (Koistinaho and Koistinaho, 2002), and there is increasing evidence that p38 MAPK inhibitors can protect against microglia-induced neurotoxicity in vivo (Barone et al., 2001; Koistinaho and Koistinaho, 2002). Thus, we asked whether blocking microglia Kv1.3 channels might reduce their neurotoxic functions by inhibiting activation of p38 MAPK. For comparison, we assessed minocycline, a second-generation tetracycline derivative, which can be neuroprotective in vitro and in vivo (Yong et al., 2004). Minocycline inhibits p38 MAPK activation, inducible nitric oxide synthase induction, and nitric oxide production in microglia and activity of caspases 1 and 3 in neurons (Chen et al., 2000; Tikka et al., 2001; Wu et al., 2002; Lee et al., 2004; Yong et al., 2004).

Our key finding is consistent with the lack of effect of Kv blockers on NO production; that is, (unlike minocycline) the Kv1.3 blockers did not inhibit LPS-induced p38 MAPK phosphorylation, thus pointing to a separate intracellular pathway mediating the neurotoxic effects of activated microglia. Although it will be interesting to determine the downstream events affected by blocking Kv1.3 channels in microglia, such signaltransduction pathways might not be as amenable to therapeutic interventions as the channels themselves.

The present results may have broad implications for controlling neuroinflammation, because microglia are often the first cells to respond to brain injury or disease (Gehrmann et al., 1995; Aloisi, 2001; Streit, 2002). Furthermore, microglial activation is associated with pathogenesis in both acute and chronic disease states, including bacterial infection, human immunodeficiency virus, amyotrophic lateral sclerosis, multiple sclerosis, prion disease, retinal degeneration, brain trauma, and ischemic stroke (Kreutzberg, 1996; GonzalezScarano and Baltuch, 1999; Stollg and Jander, 1999; Nelson et al., 2002; Polazzi and Contestabile, 2002). The present study provides the first evidence that a specific $\mathrm{K}^{+}$channel can regulate the neurotoxic properties of microglia. Moreover, the restricted cellular expression and roles of Kv1.3 in the CNS mean that selective Kv1.3 blockers might provide a novel anti-inflammatory strategy in CNS injury and disease. Kv1.3 is predominantly expressed in cells of the immune system, including microglia, lymphocytes, and macrophages, and many studies show that this channel is important for activation of T lymphocytes (for review, see Cahalan et al., 2001; Schlichter and Khanna 2002; Chandy et al., 
2004). Some peptide inhibitors of Kv1.3 have already been tested in vivo in animal models of delayed-type hypersensitivity (Koo et al., 1997) and the experimental autoimmune encephalomyelitis model of multiple sclerosis (for review, see Cahalan et al., 2001; Chandy et al., 2004). Potential side effects might be minimal despite the presence of small amounts of Kv1.3 in some neurons in the CNS (i.e., in a small subset of neurons in the hippocampus, pyriform cortex, and olfactory bulb) (Kues and Wunder, 1992). For instance, the only CNS deficit observed in Kv1.3-deficient mice was hypersensitivity to odorants caused by defects in the development of the olfactory bulb (Fadool et al., 2004). Thus, the potential for developing Kv1.3 blockers to inhibit neuroinflammation is good, particularly because new classes of nonpeptidyl blockers with high specificity and better pharmacodynamics are being developed as immunosuppressants for organ and tissue transplant (for review, see Cahalan et al., 2001; Chandy et al., 2004).

\section{References}

Ajmone-Cat MA, De Simone R, Nicolini A, Minghetti L (2003) Effects of phosphatidylserine on $\mathrm{p} 38$ mitogen activated protein kinase, cyclic AMP responding element binding protein and nuclear factor-kappaB activation in resting and activated microglial cells. J Neurochem 84:413-416.

Aloisi F (2001) Immune function of microglia. Glia 36:165-179.

Bal-Price A, Brown GC (2001) Inflammatory neurodegeneration mediated by nitric oxide from activated glia-inhibiting neuronal respiration, causing glutamate release and excitotoxicity. J Neurosci 21:6480-6491.

Bal-Price A, Matthias A, Brown GC (2002) Stimulation of the NADPH oxidase in activated rat microglia removes nitric oxide but induces peroxynitrite production. J Neurochem 80:73-80.

Banati RB, Rothe G, Valet G, Kreutzberg GW (1991) Respiratory burst activity in brain macrophages: a flow cytometric study on cultured rat microglia. Neuropathol Appl Neurobiol 17:223-230.

Barone FC, Irving EA, Ray AM, Lee JC, Kassis S, Kumar S, Badger AM, Legos JJ, Ehrhardt JA, Ohlstein EH, Hunter AJ, Harrison DC, Philpott K, Smith BR, Adams JL, Parsons AA (2001) Inhibition of p38 mitogen-activated protein kinase provides neuroprotection in cerebral focal ischemia. Med Res Rev 21:129-145.

Boje KM, Arora PK (1992) Microglial-produced nitric-oxide and reactive nitrogen-oxides mediate neuronal cell-death. Brain Res 587:250-256.

Brewer GJ (1997) Isolation and culture of adult rat hippocampal neurons. J Neurosci Methods 71:143-155.

Brown H, Kozlowski R, Perry H (1998) The importance of ion channels for macrophage and microglial activation in vitro. Glia 22:94-97.

Cahalan MD, Wulff H, Chandy KG (2001) Molecular properties and physiological roles of ion channels in the immune system. J Clin Immunol 21:235-252.

Cayabyab FS, Khanna R, Jones OT, Schlichter LC (2000) Suppression of the rat microglia Kv1.3 current by src-family tyrosine kinases and oxygen/ glucose deprivation. Eur J Neurosci 12:1949-1960.

Chandy KG, Wulff H, Beeton C, Pennington M, Gutman GA, Cahalan MD (2004) $\mathrm{K}^{+}$channels as targets for specific immunomodulation. Trends Pharmacol Sci 25:280-289.

Chao CC, Hu SX, Molitor TW, Shaskan EG, Peterson PK (1992) Activated microglia mediate neuronal cell injury via a nitric-oxide mechanism. J Immunol 149:2736-2741.

Chen M, Ona VO, Li M, Ferrante RJ, Fink KB, Zhu S, Bian J, Guo L, Farrell LA, Hersch SM, Hobbs W, Vonsattel JP, Cha JH, Friedlander RM (2000) Minocycline inhibits caspase- 1 and caspase- 3 expression and delays mortality in a transgenic mouse model of Huntington disease. Nat Med 6:797-801.

Chung I, Schlichter LC (1997a) Native Kv1.3 channels are upregulated by protein kinase C. J Membr Biol 156:73-85.

Chung I, Schlichter LC (1997b) Regulation of native Kv1.3 channels by cAMP-dependent protein phosphorylation. Am J Physiol 273:C622-C633.

Colton CA, Jia M, Li MX, Gilbert DL (1994) $\mathrm{K}^{+}$modulation of microglial superoxide production: involvement of voltage-gated $\mathrm{Ca}^{2+}$ channels. Am J Physiol 266:C1650-C1655.

Dijkstra S, Geisert Jr EE, Dijkstra CD, Bar PR, Joosten EA (2001) CD81 and microglial activation in vitro: proliferation, phagocytosis and nitric oxide production. J Neuroimmunol 114:151-159.

Eder C (1998) Ion channels in microglia (brain macrophages). Am J Physiol 275:C327-C342.

Eder C, Klee R, Heinemann U (1997) Distinct soluble astrocytic factors induce expression of outward $\mathrm{K}^{+}$currents and ramification of brain macrophages. Neurosci Lett 226:147-150.

Evans MS, Collings MA, Brewer GJ (1998) Electrophysiology of embryonic, adult and aged rat hippocampal neurons in serum-free culture. J Neurosci Methods 79:37-46.

Fadool DA, Tucker K, Perkins R, Fasciani G, Thompson RN, Parsons AD, Overton JM, Koni PA, Flavell RA, Kaczmarek LK (2004) Kv1.3 channel gene-targeted deletion produces "Super-smeller mice" with altered glomeruli, interacting scaffolding proteins, and biophysics. Neuron 41:389-404.

Garcia ML, Hanner M, Knaus HG, Kach R, Schmalhofer W, Slaughter RS, Kaczorowski GJ (1997) Pharmacology of potassium channels. Adv Pharmacol 39:425-471.

Gebicke-Haerter PJ, Van Calker D, Norenberg W, Illes P (1996) Molecular mechanisms of microglial activation. A. Implications for regeneration and neurodegenerative diseases. Neurochem Int 29:1-12.

Gehrmann J, Matsumoto Y, Kreutzberg GW (1995) Microglia: intrinsic immuneffector cell of the brain. Brain Res Brain Res Rev 20:269-287.

Gonzalez-Scarano F, Baltuch G (1999) Microglia as mediators of inflammatory and degenerative diseases. Annu Rev Neurosci 22:219-240.

Green LC, Wagner DA, Glogowski J, Skipper PL, Wishnok JS, Tannenbaum SR (1982) Analysis of nitrate, nitrite, and [15N]nitrate in biological fluids. Anal Biochem 126:131-138.

Grissmer S, Nguyen AN, Aiyar J, Hanson DC, Mather RJ, Gutman GA, Karmilowicz MJ, Auperin DD, Chandy KG (1994) Pharmacological characterization of five cloned voltage-gated $\mathrm{K}^{+}$channels, types Kv1.1, $1.2,1.3,1.5$, and 3.1, stably expressed in mammalian cell lines. Mol Pharmacol 45:1227-1234.

Jeohn GH, Cooper CL, Jang KJ, Liu B, Lee DS, Kim HC, Hong JS (2002) Go6976 inhibits LPS-induced microglial TNFalpha release by suppressing p38 MAP kinase activation. Neuroscience 114:689-697.

Khanna R, Roy L, Zhu X, Schlichter LC (2001) $\mathrm{K}^{+}$channels and the microglial respiratory burst. Am J Physiol Cell Physiol 280:C796-C806.

Kim JA, Kang YS, Jung MW, Kang GH, Lee SH, Lee YS (2000) $\mathrm{Ca}^{2+}$ influx mediates apoptosis induced by 4 -aminopyridine, a $\mathrm{K}^{+}$channel blocker, in HepG2 human hepatoblastoma cells. Pharmacology 60:74-81.

Koistinaho M, Koistinaho J (2002) Role of p38 and p44/42 mitogenactivated protein kinases in microglia. Glia 40:175-183.

Koo GC, Blake JT, Talento A, Nguyen M, Lin S, Sirotina A, Shah K, Mulvany K, Hora Jr D, Cunningham P, Wunderler DL, McManus OB, Slaughter R, Bugianesi R, Felix J, Garcia M, Williamson J, Kaczorowski GT, Sigal NH, Springer MS, et al. (1997) Blockade of the voltage-gated potassium channel Kv1.3 inhibits immune responses in vivo. J Immunol 158:5120-5128.

Kotecha SA, Schlichter LC (1999) A Kv1.5 to Kv1.3 switch in endogenous hippocampal microglia and a role in proliferation. J Neurosci 19:10680-10693.

Kreutzberg GW (1996) Microglia: a sensor for pathological events in the CNS. Trends Neurosci 19:312-318.

Kues WA, Wunder F (1992) Heterogeneous expression patterns of mammalian potassium channel genes in developing and adult rat brain. Eur J Neurosci 4:1296-1308.

Lee SM, Yune TY, Kim SJ, Kim YC, Oh YJ, Markelonis GJ, Oh TH (2004) Minocycline inhibits apoptotic cell death via attenuation of TNF- $\alpha$ expression following iNOS/NO induction by lipopolysaccharide in neuron/ glia co-cultures. J Neurochem 91:568-578.

Lieb K, Engels S, Fiebich BL (2003) Inhibition of LPS-induced iNOS and NO synthesis in primary microglial cells. Neurochem Int 42:131-137.

Misko TP, Highkin MK, Veenhuizen AW, Manning PT, Stern MK, Currie MG, Salvemini D (1998) Characterization of the cytoprotective action of peroxynitrite decomposition catalysts. J Biol Chem 273:15646-15653.

Morimoto K, Murasugi T, Oda T (2002) Acute neuroinflammation exacerbates excitotoxicity in rat hippocampus in vivo. Exp Neurol 177:95-104.

Nakamura Y, Si QS, Kataoka K (1999) Lipopolysaccharide-induced microglial activation in culture: temporal profiles of morphological change and release of cytokines and nitric oxide. Neurosci Res 35:95-100. 
Nelson PT, Soma LA, Lavi E (2002) Microglia in diseases of the central nervous system. Ann Med 34:491-500.

Norenberg W, Gebicke-Haerter PJ, Illes P (1994) Voltage-dependent potassium channels in activated rat microglia. J Physiol (Lond) 475:15-32.

Polazzi E, Contestabile A (2002) Reciprocal interactions between microglia and neurons: from survival to neuropathology. Rev Neurosci 13:221-242.

Pyo H, Chung S, Jou I, Gwag B, Joe EH (1997) Expression and function of outward $\mathrm{K}^{+}$channels induced by lipopolysaccharide in microglia. Mol Cells 7:610-614.

Schlichter LC, Khanna R (2002) $\mathrm{K}^{+}$channels and proliferation in neuroimmune cells. In: Roles of ion channels in physiopathology of nerve conduction and cell proliferation (Rouzaire-Dubois B, Benoit E, Dubois J-M, eds), pp 121-151. Karala, India: Research Signpost.

Schlichter LC, Sakellaropoulos G, Ballyk B, Pennefather PS, Phipps DJ (1996) Properties of $\mathrm{K}^{+}$and $\mathrm{Cl}^{-}$channels and their involvement in proliferation of rat microglial cells. Glia 17:225-236.

Smith ME, van der MK, Somera FP, Sobel RA (1998) Effects of phorbol myristate acetate (PMA) on functions of macrophages and microglia in vitro. Neurochem Res 23:427-434.

Spranger M, Kiprianova I, Krempien S, Schwab S (1998) Reoxygenation increases the release of reactive oxygen intermediates in murine microglia. J Cereb Blood Flow Metab 18:670-674.

Stollg G, Jander S (1999) The role of microglia and macrophages in the pathophysiology of the CNS. Prog Neurobiol 58:233-247.

Streit WJ (2002) Microglia as neuroprotective, immunocompetent cells of the CNS. Glia 40:133-139.

Streit WJ, Walter SA, Pennell NA (1999) Reactive microgliosis. Prog Neurobiol 57:563-581.

Tikka T, Fiebich BL, Goldsteins G, Keinanen R, Koistinaho J (2001) Mino- cycline, a tetracycline derivative, is neuroprotective against excitotoxicity by inhibiting activation and proliferation of microglia. J Neurosci 21:2580-2588.

van der Veen RC, Hinton DR, Incardonna F, Hofman FM (1997) Extensive peroxynitrite activity during progressive stages of central nervous system inflammation. J Neuroimmunol 77:1-7.

Visentin S, Levi G (1997) Protein kinase C involvement in the resting and interferon-gamma-induced $\mathrm{K}^{+}$channel profile of microglial cells. J Neurosci Res 47:233-241.

Wei L, Yu S-P, Gottron F, Snider J, Zipfel GJ, Choi DW (2003) Potassium blockers attenuate hypoxia- and ischemia-induced neuronal death in vitro and in vivo. Stroke 34:1281-1286.

Wu DC, Jackson-Lewis V, Vila M, Tieu K, Teismann P, Vadseth C, Choi DK, Ischiropoulos H, Przedborski S (2002) Blockade of microglial activation is neuroprotective in the 1-methyl-4-phenyl-1,2,3,6-tetrahydropyridine mouse model of Parkinson disease. J Neurosci 22:1763-1771.

Wulff H, Gutman GA, Chandy KG (2003) Potassium channels as therapeutic targets for autoimmune disorders. Curr Opin Drug Discov Devel 6:640-647.

Xie Z, Wei M, Morgan TE, Fabrizio P, Han D, Finch CE, Longo VD (2002) Peroxynitrite mediates neurotoxicity of amyloid $\beta$-peptide ${ }_{1-42^{-}}$and lipopolysaccharide-activated microglia. J Neurosci 22:3484-3492.

Yong VW, Wells J, Giuliani F, Casha S, Power C, Metz LM (2004) The promise of minocycline in neurology. Lancet Neurol 3:744-751.

Zietlow R, Dunnett SB, Fawcett JW (1999) The effect of microglia on embryonic dopaminergic neuronal survival in vitro: diffusible signals from neurons and glia change microglia from neurotoxic to neuroprotective. Eur J Neurosci 11:1657-1667. 